\title{
In Vivo Expression of miR-32 Induces Proliferation in Prostate Epithelium
}

\author{
Leena Latonen, ${ }^{* \dagger}$ Mauro Scaravilli, ${ }^{* \dagger}$ Andrew Gillen, ${ }^{* \dagger}$ Samuli Hartikainen, ${ }^{* \dagger}$ Fu-Ping Zhang, ${ }^{\ddagger}$ Pekka Ruusuvuori, ${ }^{*} \delta$
} Paula Kujala, ${ }^{\dagger}$ Matti Poutanen, ${ }^{\star \top}$ and Tapio Visakorpi ${ }^{* \dagger}$

From the Prostate Cancer Research Center, * Faculty of Medicine and Life Sciences and BioMediTech, University of Tampere, Tampere; the Fimlab Laboratories, ${ }^{\dagger}$ Tampere University Hospital, Tampere; the Turku Center for Disease Modeling ${ }^{\ddagger}$ and the Department of Physiology, "Institute of Biomedicine, University of Turku, Turku; and the Tampere University of Technology, ${ }^{\S}$ Pori, Finland

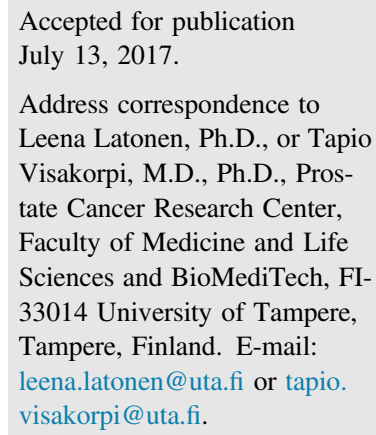

\begin{abstract}
miRNAs are important regulators of gene expression and are often deregulated in cancer. We have previously shown that miR-32 is an androgen receptor-regulated miRNA overexpressed in castrationresistant prostate cancer and that miR-32 can improve prostate cancer cell growth in vitro. To assess the effects of miR-32 in vivo, we developed transgenic mice overexpressing miR-32 in the prostate. The study indicated that transgenic miR-32 expression increases replicative activity in the prostate epithelium. We further observed an aging-associated increase in the incidence of goblet cell metaplasia in the prostate epithelium. Furthermore, aged miR-32 transgenic mice exhibited metaplasia-associated prostatic intraepithelial neoplasia at a low frequency. When crossbred with mice lacking the other allele of tumor-suppressor Pten (miR-32xPten ${ }^{+/-}$mice), miR-32 expression increased both the incidence and the replicative activity of prostatic intraepithelial neoplasia lesions in the dorsal prostate. The miR$32 x$ Pten $^{+/-}$mice also demonstrated increased goblet cell metaplasia compared with Pten ${ }^{+/-}$mice. By performing a microarray analysis of mouse prostate tissue to screen downstream targets and effectors of miR-32, we identified $R A C 2$ as a potential, and clinically relevant, target of miR-32. We also demonstrate down-regulation of several interesting, potentially prostate cancer-relevant genes (Spink1, Spink5, and Casp1) by miR-32 in the prostate tissue. The results demonstrate that miR-32 increases proliferation and promotes metaplastic transformation in mouse prostate epithelium, which may promote neoplastic alterations in the prostate. (Am J Pathol 2017, 187: 2546-2557; http://dx.doi.org/ 10.1016/j.ajpath.2017.07.012)
\end{abstract}

Prostate cancer (PC) is the second most common cancer in men and the sixth leading cause of cancer-related deaths in males worldwide. ${ }^{1}$ Localized PC can be cured with prostatectomy and/or radiation therapy. However, there is no curative treatment for castration-resistant $\mathrm{PC}$, the advanced form of the disease. ${ }^{2}$ The use of prostate-specific antigen for screening of asymptomatic men for PC reduces diseasespecific mortality, but screening is also associated with overdiagnosis. $^{3}$ Therefore, additional markers are required for PC diagnosis and prognosis, as well as for therapeutic targets.

miRNAs are small, approximately 22-nucleotide long, noncoding RNA molecules able to modulate gene expression by binding to a complementary sequence at the $3^{\prime}$-end untranslated region of their target mRNAs. ${ }^{4,5}$ Binding of an miRNA leads to either degradation of the mRNA or, alternatively, suppression of translation of the mRNA. ${ }^{5,6}$ As one miRNA can have multiple targets and a particular mRNA can be targeted by several miRNAs, miRNAs are parts of complex networks regulating gene expression. ${ }^{7}$ Several miRNAs have been shown to be deregulated in PC, leading

\footnotetext{
Supported by Academy of Finland grant 279270, the Cancer Society of Finland, the Sigrid Juselius Foundation, the Medical Research Fund of Tampere University Hospital, and the Finnish Funding Agency for Innovation (project three-dimensional histogenomic modeling of whole prostate).
}

Disclosures: None declared. 
to aberrant regulation of apoptosis, cell cycle, intracellular signaling, DNA repair, cell adhesion/migration, and androgen signaling. ${ }^{8}$ miRNAs are most often encoded in the genome as independent or clustered genes, or produced as intronic miRNAs cleaved off from the transcripts of parental genes. ${ }^{6}$ The RNA polymerase II-produced pri-miRNAs form hairpin structures that are cleaved by the Drosha ribonuclease III, resulting in a 70-nucleotide precursor miRNA (pre-miRNA). The pre-miRNA is further cleaved by Dicer ribonuclease to generate a mature miRNA and an antisense star miRNA product (alias $5^{\prime}$ and $3^{\prime}$ miRNAs, respectively). The produced miRNA is then linked to an RNA-induced silencing complex, which directs the attachment of the miRNA to the target mRNA with imperfect base pairing. ${ }^{5,6}$

As miRNAs are important regulators of gene expression and often deregulated in cancer, ${ }^{9}$ the question has arisen whether they can serve as cancer markers and/or drug targets in several cancers, including PC. ${ }^{8}$ Several studies assess alterations of miRNA expression levels in $\mathrm{PC},{ }^{10-17}$ and their potential role as PC biomarkers has been recognized. ${ }^{18}$ Furthermore, several individual miRNAs are functionally important in PC. ${ }^{8,19} \mathrm{We}^{20}$ and others ${ }^{21-23}$ have shown that miR-32 is one of the miRNAs whose expression is most consistently increased in PC, especially at the castrationresistant stage. Elevated expression of miR-32 increases proliferation and decreases apoptosis of PC cells in vitro, ${ }^{20,24}$ but so far, no evidence for in vivo functions of miR-32 in the prostate exists. miR-32 has dozens of predicted and several verified targets; however, little consistency exists between the targets identified in different assays and models. miR-32 has been previously shown to posttranscriptionally down-regulate the tumor-suppressor gene Pten in colorectal and hepatocellular cancers. ${ }^{25,26}$ In prostate cancer, targets identified previously in cell culture experiments include the proapoptotic protein BIM (BCL2L11) and the antiproliferative protein BTG2. ${ }^{20,21}$

To better understand the possible role of miR-32 in prostate cancer, we wanted to assess the physiological effects of increased expression of miR-32 in the prostate in vivo. By the use of transgenic (TG) mice, we show that miR-32 induces transcriptional and transformative changes in mouse prostate, leading to induced proliferation and metaplastic alterations of prostate epithelium.

\section{Materials and Methods}

\section{Cloning and Verification of the Transgene}

DNA oligomers containing a 110-bp mouse genomic sequence with pre-miR-32, flanked by 20 nucleotides on each side, were purchased from Sigma-Aldrich (St. Louis, MO). At the ends, restriction sites for EcoRI and XhoI were present, and were used for cloning the fragment into pCDNA3. $1^{+}$(Thermo Fisher Scientific, Waltham, MA). Thereafter, the insert containing the miR-32 sequence, followed by the bovine growth hormone poly(A) sequence, was amplified by PCR using primers, including a $3^{\prime}$ BamHI site and a $5^{\prime}$ SacI site. The resulting fragment was inserted into the pBluescriptSKII-ARR2PB plasmid (a gift from Dr. Robert J. Matusik, Department of Urologic Surgery, Vanderderbilt University Medical Center, Nashville, TN). Successful cloning was verified with Sanger sequencing. The androgen-dependent expression of the construct was tested after transfecting it to LNCaP PC cells (ATCC, Manassas, VA) by previously described methods. ${ }^{27,28}$ For transgene injections, a linearized fragment of $1118 \mathrm{bp}$, containing miR-32 and the regulatory sequences, was excised from the plasmid with restriction enzymes KpnI and SacI, followed by purification using the QIAquick Gel extraction kit (Qiagen, Hilden, Germany).

\section{Mice and Genotyping}

TG miR-32 mice were produced in FVB/N strain by pronuclear injection of fertilized oocytes using standard techniques. All animal experimentation and care procedures were performed in accordance with guidelines and regulations of the national Animal Experiment Board of Finland, and were approved by the board of laboratory animal work of the Regional State Administrative Agency for Southern Finland (licence number ESAVI/6271/ 04.10.03/2011). DNA for genotyping was extracted from ear samples by overnight incubation at $55^{\circ} \mathrm{C}$ in tissue lysis buffer $(100 \mathrm{mmol} / \mathrm{L}$ Tris, $\mathrm{pH} 8,300 \mathrm{mmol} / \mathrm{L} \mathrm{NaCl}$, and $10 \mathrm{mmol} / \mathrm{L}$ EDTA) supplemented with $1 \%$ SDS and $200 \mathrm{ng} / \mathrm{mL}$ proteinase $\mathrm{K}$, followed by standard ethanol precipitation. Genotyping was performed by real-time quantitative PCR (qPCR) using Maxima SYBR Green (Thermo Fisher Scientific), according to the manufacturer's instructions. The primers used for the transgene amplification were the following: 5'-GATGACACAATGTCAATGTCTGTGTA-3' (forward) and $5^{\prime}$ CCGTGACAACATGCAACTTAG-3' (reverse). TG miR-32 mice with generations $F_{2}$ to $F_{4}$ were used in these studies. Mice heterozygous for tumor-suppressor Pten $^{29}$ in FVB/N background were obtained from Dr. Christopher Albanese (Georgetown University, Washington, DC). The mice were genotyped by PCR using DyNAzyme II DNA polymerase (Thermo Fisher Scientific) with primers recognizing the wild-type (wt) allele $\left[5^{\prime}\right.$ CTGAGTCATCAATTCTCTAAGATTCTTC-3' (forward); $5^{\prime}$ GAAAAACGTGTTTTCTCTCATGGGA-3'(reverse)] and the deleted allele [5'-CCCGGTGCCTTTTAAGGTTTGTTTTATTAT-3' (forward); 5'-AGGCCACTTGTGTAGCGCC-3' (reverse)]. Actb was amplified as a reference gene in both qPCR and PCR using the following primers: 5'-CGAGCGGTTCCGATGCCCTG-3' (forward) and 5'-ACGCAGCTCAGTAACAGTCCGC-3' (reverse).

\section{Tissue Samples and Histological Assessment}

Tissues were fixed in either formalin or PAXgene molecular fixative (PreAnalytiX GmbH, Hombrechtikon, Switzerland), according to the manufacturer's recommendations, and 
embedded in paraffin. The prostate blocks were sectioned through, and all of the sections ( $5 \mu \mathrm{m}$ thick) were collected for further use. The histology throughout the prostate was analyzed on hematoxylin and eosin-stained sections every $50 \mu \mathrm{m}$ apart. Sections were whole slide imaged with a Zeiss Axioskop40 microscope (Carl Zeiss MicroImaging, Jena, Germany) using a $20 \times$ objective, a charge-coupled device color camera (QICAM Fast; QImaging, Surrey, BC, Canada), and a motorized specimen stage (Märzhäuser Wetzlar $\mathrm{GmbH}$, Wetzlar, Germany). The automated image acquisition was controlled by the Surveyor imaging system (Objective Imaging, Cambridge, UK). Uncompressed bitmap outputs were converted by JVSdicom Compressor application to JPEG2000 WSI format, ${ }^{30}$ from which snapshot images were obtained through a JVSView virtual microscope (http://jvsmicroscope.uta.fi, last accessed June 18, $2017)^{31}$ and ImageJ software version 1.45s (NIH, Bethesda, MD; https://imagej.nih.gov/ij). ${ }^{32}$

The prostatic intraepithelial neoplasia (PIN) lesions were assessed according to the grading described by Park et al. ${ }^{33}$ Analysis of lesion sizes was performed by image analysis from subsampled whole slide images. For this, regions of interest were manually determined, and their areas were calculated using ImageJ. To take into account the third dimension, we determined the PIN lesion size as the sum of pixels of the areas with a particular PIN lesion observed in all of the sections at $50-\mu \mathrm{m}$ intervals.

\section{Periodic Acid-Schiff Staining}

Periodic acid-Schiff staining was performed by soaking the tissue slides in $0.5 \%$ periodic acid (Sigma-Aldrich) solution for 5 minutes, followed by washing in water, then incubating in Schiff reagent (Merck, Kenilworth, NJ) for 15 minutes, followed by a second washing with water. Counterstaining was performed by Mayer's hematoxylin (Histolab Products AB, Gothenburg, Sweden).

\section{Immunohistochemistry}

Sections were deparaffinized, and antigen retrieval was performed by incubating the sections at $98^{\circ} \mathrm{C}$ for $15 \mathrm{mi}-$ nutes in Tris-EDTA buffer $(\mathrm{pH} 9)$, supplemented with 0.05\% Tween-20. The staining was performed by Lab Vision Autostainer (Thermo Fisher Scientific), using antibodies against cleaved caspase-3 (Asp175; clone D3E9; Cell Signaling Technology, Danvers, MA), Ki-67 (Sp6; Thermo Fisher Scientific), proliferating cell nuclear antigen (PCNA; PC10; Cell Signaling Technology), phosphorylated histone H3 (Ser10; Cell Signaling Technology), and phosphorylated S6 ribosomal protein (Ser235/236; Cell Signaling Technology), and followed by a secondary antibody (N-Histofine Simple Stain MAX PO; Nichirei, Tokyo, Japan). ImmPACT diaminobenzidine (Vector Laboratories, Burlingame, CA) was used as a chromogen. The sections were counterstained with hematoxylin, mounted with DPX mounting medium (Sigma-Aldrich), and digitized as described above. Assessment of cells positive for cleaved caspase-3, Ki-67, PCNA, and phosphorylated histone H3 stainings was performed manually with the ImageJ cell counter. Between 500 and 3000 nuclei were counted per sample, and the number of antibody-stained positive nuclei relative to counterstained nuclei was calculated. For phosphorylated S6 ribosomal protein, quantitation for staining intensity was performed by extracting PIN areas from whole slide images in ImageJ and analyzing the staining ratio of brown staining to the mask area of the PIN lesion. The area of brown staining was estimated through thresholding the red/blue signal ratio. A global threshold of 1.3 was applied to all PIN lesion images. The lesion mask area was calculated from the image by excluding all background signal (essentially white pixels with intensity $>225$ in eightbit format).

\section{RNA Extraction}

Tissues of wt and TG miR-32 mice for RNA extraction were collected and stored in RNAlater (Thermo Fisher Scientific). RNA was extracted with manual homogenization by pressing a sample repeatedly through 20 - to 22 -gauge needles and using TriReagent (Sigma-Aldrich), according to manufacturer's instructions.

RNA from heterozygous phosphatase and tensin homologue (PTEN) model mice was extracted from tissues of 4-month-old mice. Prostates were fixed in PAXgene molecular fixative (PreAnalytiX $\mathrm{GmbH}$ ) and embedded in paraffin. The prostate blocks were sectioned, and $10 \mathrm{sec}-$ tions $(5 \mu \mathrm{m}$ thick) were used for RNA extraction with PAXgene Tissue RNA Kit (PreAnalytiX GmbH). Adjacent, hematoxylin and eosin-stained sections were used to confirm that the sections in RNA extractions contained material from all prostate lobes.

\section{RT-qPCR}

Quantitative RT-PCR (RT-qPCR) for assessing potential miR32 target levels was performed by the SYBR Green method. cDNA was made using Maxima RT reverse transcriptase (Thermo Fisher Scientific). RT-qPCRs were performed with the CFX96 q-RT-PCR detection system (Bio-Rad Laboratories Inc., Hercules, CA) using Maxima SYBR Green (Fermentas Inc., Burlington, ON, Canada). Actb was used as a reference gene for mouse samples, and $T B P$ was used for human samples. The primer sequences that were used are as follows: B-actin, $5^{\prime}$ CGAGCGGTTCCGATGCCCTG-3' (forward) and $5^{\prime}$-ACGCAGCTCAGTAACAGTCCGC-3' (reverse); Rac2, $5^{\prime}$ GGGTACCTCCTAGCCACTCC- $3^{\prime}$ (forward) and $5^{\prime}$ GAGAAGACACGTCTTGCCCA-3' (reverse); caspase 1 (Casp1), 5'-CTGGCAGGAATTCTGGAGCTT-3' (forward) and $5^{\prime}$-CTTGAGGGTCCCAGTCAGTC-3' (reverse); Spink1, 5'-CTTCTCAGTGCTTTGGCCCT-3' (forward) and $5^{\prime}$ AAATTCTGGGACATCCCGCC-3' (reverse); Spink5, 

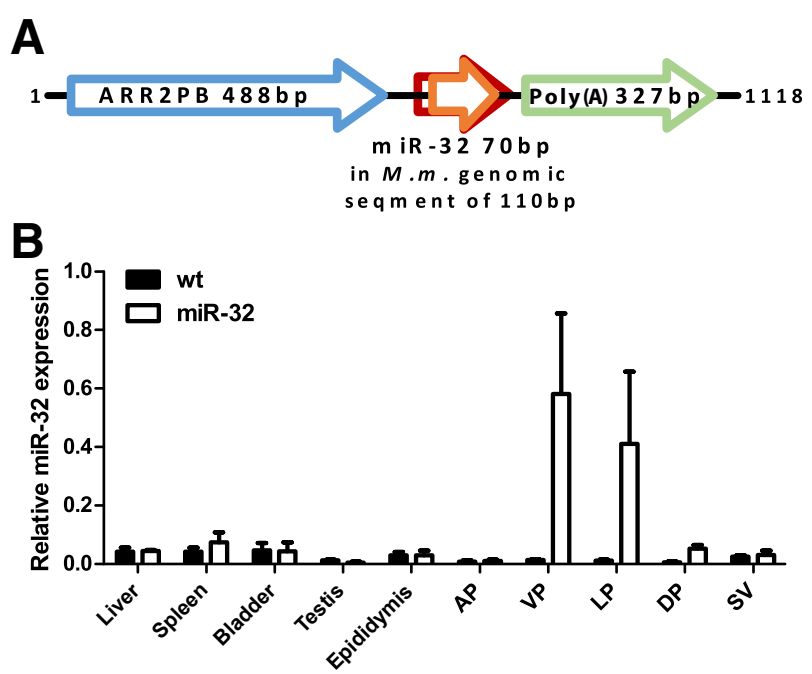

Figure 1 Transgenic expression of miR-32 in the mouse prostate. A: Structure of the androgen-responsive rat probasin promoter (ARR2PB)miR-32 transgene. The mouse pre-miR-32 (orange) was flanked by 20 bp of mouse genomic sequence on each side (red), preceded with ARR2PB (blue) and followed by bovine growth hormone poly(A) signal (green). B: Expression of miR-32 in mouse prostate lobes and other mouse tissues assessed by TaqMan assay in wild-type (wt) and miR-32 transgenic (miR32) mice. Data are expressed as means \pm SEM. $n=6$ in each group (B). $\mathrm{AP}$, anterior prostate; DP, dorsal prostate; LP, lateral prostate; M.m., Mus musculus; SV, seminal vesicle; VP, ventral prostate.

$5^{\prime}$-GAGTTCCAGTGGTGGGAACC-3' (forward) and $5^{\prime}$ CCCGAGTGCAGAGGAGTTTC-3' (reverse); TBP, 5'-GGGGAGCTGTGATGTGAAGT-3' (forward) and $5^{\prime}$-GAGCCATTACGTCGTCTTCC-3' (reverse); and RAC2, 5'-CGCCAAGTGGTTCCCAGAA- $3^{\prime}$ (forward) and $5^{\prime}$-GCTGAGCACTCCAGGTATTTCA-3' (reverse).

RT-qPCR for miRNAs was performed using the TaqMan microRNA Assay (Applied Biosystems, Foster City, CA) and the CFX96 q-RT-PCR detection system, according to the manufacturers' recommendations. miR-32 expression was normalized to RNU6B expression.

\section{Microarray Analysis and miRNA Target Prediction}

Global mRNA expression data were obtained using Agilent Mouse Gene Expression Array 44K (Agilent Tehcnologies, Santa Clara, CA), according to manufacturer's protocols. Samples of 6-month-old wt $(n=6)$ and miR-32 TG $(n=6)$ mouse prostates were pooled for analysis. Normalization was performed to sample wise means. The original data are submitted to Gene Expression Omnibus (https://www.ncbi. nlm.nih.gov/geo; accession number GSE100477). Genes detected in both samples, and with an expression change over the threshold of two, were considered significantly altered. Functional classification of the altered genes was performed with The PANTHER (Protein ANalysis THrough Evolutionary Relationships) Classification System version 11.1 (http://pantherdb.org, last accessed June 18, 2017). ${ }^{34}$ For the target predictions for miR-32, the
Targetscan (http://Targetscan.org, last accessed May 27, 2014), miRDB (http://mirdb.org, last accessed May 27, 2014), and microRNA.org (http://microrna.org, last accessed May 27, 2014) platforms were used.

\section{Pre-miR-32 Transfection}

The pre-miRNA transfections were performed essentially as described previously. ${ }^{20}$ Briefly, PC-3 cells (ATCC) were cultured under the recommended conditions and reverse transfected with $10 \mathrm{nmol} / \mathrm{L}$ nontargeting control or miR-32 pre-miRNA constructs (Applied Biosystems/Ambion, Austin, TX) using INTERFERin transfection reagent (Polyplus Transfection SA, Illkirch, France). RNA extraction was performed using TriReagent (Sigma-Aldrich), according to manufacturer's instructions.

\section{Statistical Analysis}

Statistical analyses were performed with GraphPad Prism statistics software version 5.02 (GraphPad Software Inc., La Jolla, CA). Differences in immunohistochemical labeling, and in the number of metaplastic lesions between controls and miR-32 TG mice, were assessed by two-tailed $t$-test. Significant differences of gene expression were evaluated by $U$-test (RT-qPCR results) and Kruskal-Wallis test (clinical samples ${ }^{35}$ ). The Fisher exact test was used to assess significance in incidence of metaplasia between control and miR-32 TG mice. The $\chi^{2}$ test was used to test significance of distribution of metaplastic lesions between prostatic lobes.

\section{Results}

\section{Transgene Expression}

In the TG mice, miR-32 was expressed specifically in mouse prostate under the control of the androgen-responsive rat probasin promoter. ${ }^{36}$ As miR-32 is an intronic miRNA processed with the aid of intron splicing, a poly(A) sequence was added to the $3^{\prime}$ end of the transgene to ensure the end of transcription (Figure 1A). A proper stimulation of the construct and the expression of the wanted product were verified by transfecting the transgene to LNCaP cells, and measuring expression of mature miR-32 with RT-qPCR after dihydrotestosterone stimulation (data not shown).

Three independent TG mouse lines were produced in the $\mathrm{FVB} / \mathrm{N}$ strain, and the expression of miR-32 in these lines was assessed at 3 and 6 months of age. The tissue expression pattern of miR-32 was identical in all three TG lines, with strong expression in the prostate (ventral, lateral, and dorsal lobes), whereas no significant expression was observed in other tissues (Figure 1B). As expected, expression of miR-32 from androgen-responsive rat probasin promoter did not result in expression in the anterior prostate, and no expression was observed in seminal vesicles either. The miR-32 TG mice of all of the three lines 
A
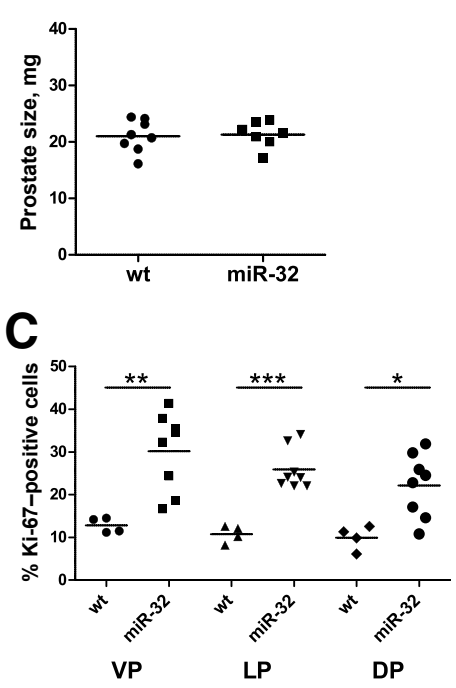

B

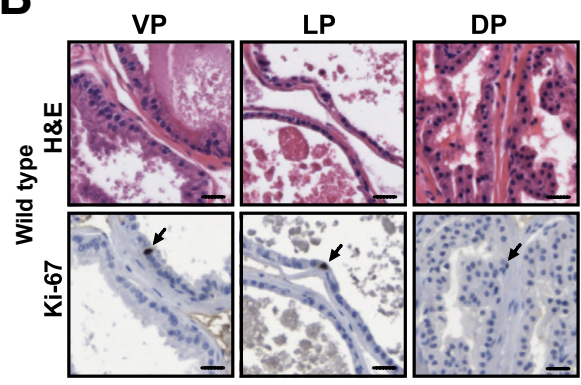

D

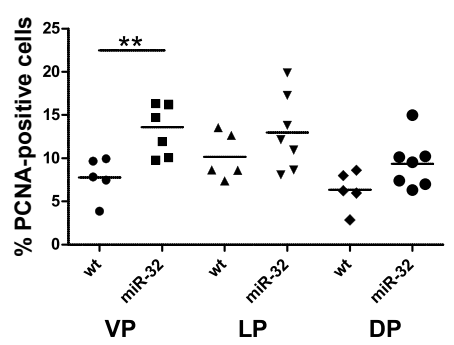

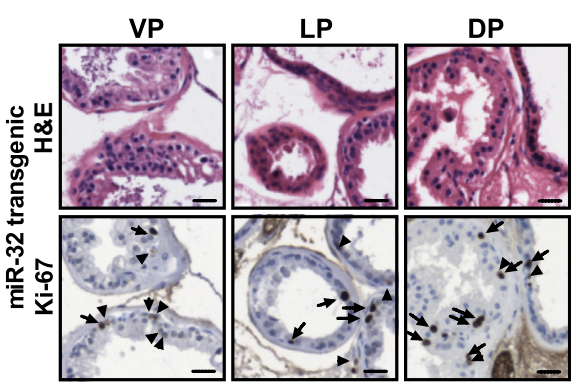

$\mathbf{E}$

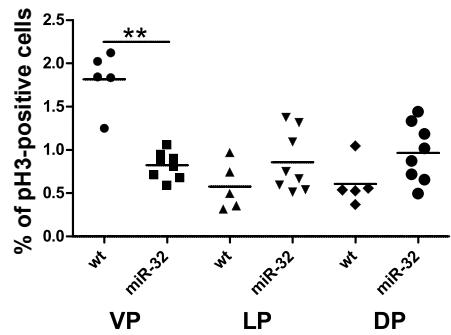

Figure 2 Expression of transgenic (TG) miR-32 promotes proliferation activity in prostate epithelium in young adult mice. A: Prostate weight in 3-monthold wild-type (wt) and miR-32 TG (miR-32) mice. B: Histology in different prostate lobes in wt and miR-32 TG mice. Top row: Hematoxylin and eosin (H\&E) staining. Bottom row: Immunohistochemical staining for Ki-67. The wt epithelium contains occasional but prominently Ki-67-positive cells (arrows), whereas the miR-32 TG epithelium has increased incidence of both prominently (arrows) and less intensely (arrowheads) Ki-67-stained nuclei. C-E: Percentages of proliferation markers Ki-67 (C) and proliferating cell nuclear antigen (PCNA; D) and mitotic marker phosphorylated histone 3 (pH3; E) expressing cells in epithelium of prostatic lobes in 3- to 6-month-old wt and miR-32 TG (miR-32) mice, as determined by immunohistochemistry. $n=8$ (A, wt mice, and C-E, miR-32 mice); $n=7$ (A, miR-32 mice); $n=4$ to 5 (C-E, wt mice). ${ }^{*} P<0.05$, ${ }^{* *} P<0.01$, and ${ }^{* * *} P<0.001$. Scale bars $=25 \mu \mathrm{m}(\mathbf{B})$. DP, dorsal prostate; LP, lateral prostate; VP, ventral prostate.

developed normally, underwent puberty, presented with macroscopically and functionally normal male reproductive tract organs (prostate, seminal vesicles, testes, and epididymis) with a weight similar to those in the wt mice (analyzed at the age of 3 to 24 months), and were fertile.

\section{Effects of miR-32 Expression in the Mouse Prostate}

Expression of miR-32 did not significantly affect gross morphology or size of the prostate measured at the age of 3 to 24 months (Figure 2A). Furthermore, no changes in tissue histology were evident at the age of 3 (wt, $n=7$; TG miR-32, $n=8$ ), 6 (wt, $n=2$; TG miR-32, $n=12$ ), 9 (wt, $n=10$; TG miR-32, $n=14$ ), or 12 (wt, $n=18$; TG miR-32, $n=14$ ) months (Figure 2B). Because miR-32 may have a role in cancer, and we have previously shown increase of it to affect cell growth and apoptosis in cell culture, we assessed markers for cell proliferation, mitotic activity, and apoptosis by immunohistochemistry of $\mathrm{wt}$ and miR-32 TG prostate tissues of mice 3 to 6 months of age. ${ }^{20}$ We observed an increase in the percentage of cells positive for replication marker Ki-67 in all lobes of the prostate in the miR-32 TG mice compared with the wt mouse prostate (Figure 2, B and C, and Supplemental Figure S1A). Although the Ki-67 staining in the positive nuclei of the normal epithelium is most often intense, spanning the whole positive nucleus in the wt prostate epithelium, in the miR-32 TG epithelium, a proportion of the Ki-67-positive nuclei contains a less intense, sometimes punctuated, staining.
We analyzed the expression of a second proliferation marker (namely, PCNA) (Figure 2D and Supplemental Figure S1B), and found a statistically significant increase in the expression $(P<0.01)$ in the miR-32 TG ventral prostate compared with the wt prostate (Figure 2D).

For a marker of mitotic cells, we used phosphorylated histone 3 (Figure 2E and Supplemental Figure S1C). The percentage of cells positive for phosphorylated histone 3 was decreased in the miR-32 TG ventral prostate $(P<0.01)$, whereas the lateral and dorsal prostates show no statistically significant change. Rather, there was a trend to the opposite direction, indicating a lobe-specific effect of TG miR-32 expression on mitotic activity of prostate epithelium in this model. Apoptotic activity, as determined by immunohistochemical staining of cleaved caspase-3, was found low in the normal prostate epithelium, as expected, with only occasional apoptotic cells found in the wt prostate epithelium $(<0.5 \%)$. TG miR-32 expression was not found to have a significant effect on the percentage of cells positive for cleaved caspase- 3 in the normal epithelium (data not shown).

In aging mice, a higher frequency of goblet cell metaplasia was detected in miR-32 TG mice compared with the wt mice, as demonstrated by periodic acid-Schiff staining (Figure 3A). In mice analyzed at the age of 16 to 24 months, metaplasia was present in $43 \%$ of the wt mice $(n=28)$, whereas $67 \%$ of miR-32 TG mice $(n=37)$ presented with metaplastic changes $(P=0.001)$. Most of the metaplastic changes in both the wt and TG mice were detected in the 
A
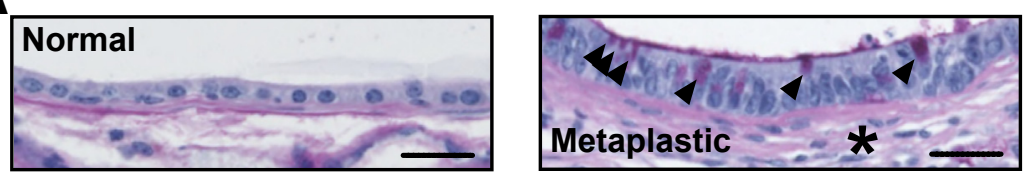

B

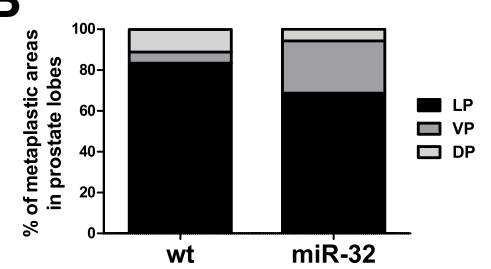

C

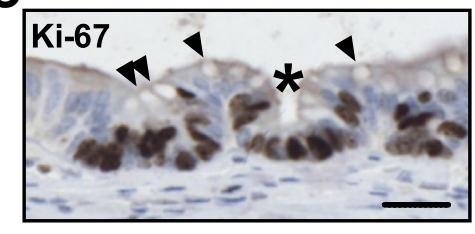

D

H\&E
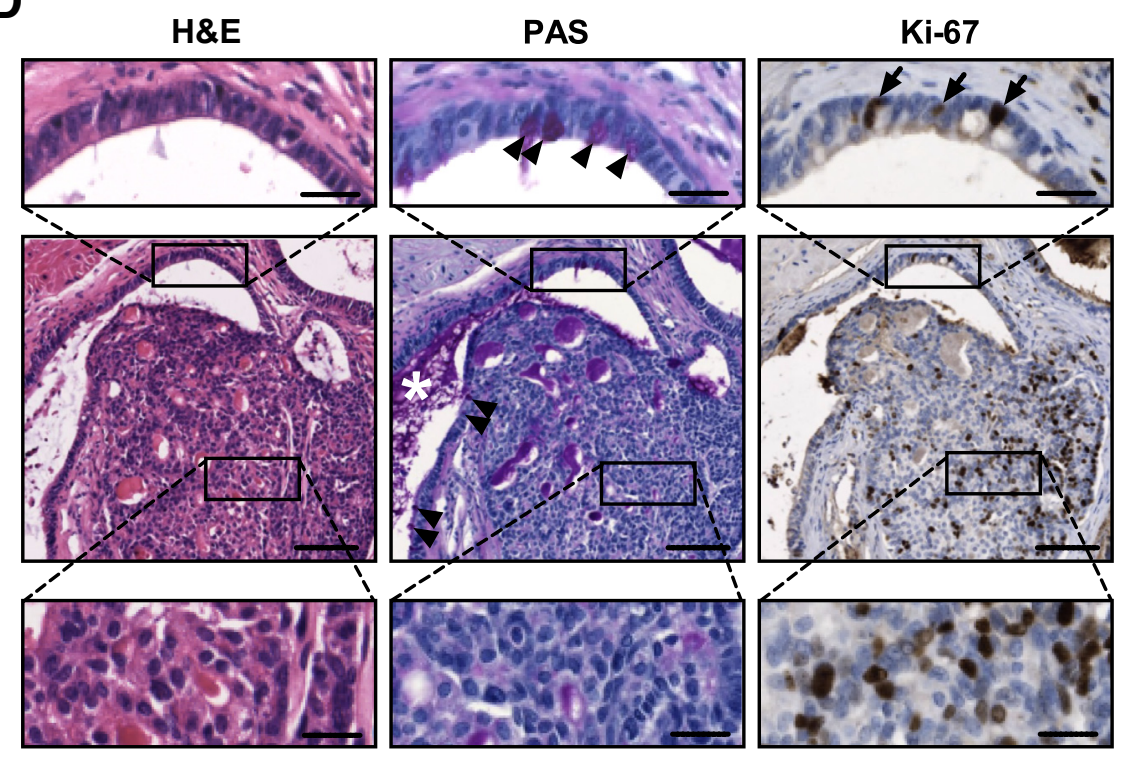

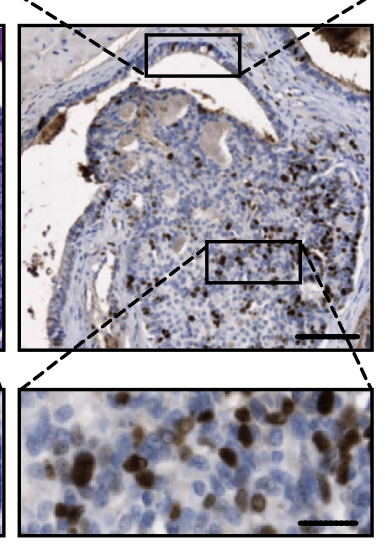

Figure 3 Expression of transgenic (TG) miR-32 promotes goblet cell metaplasia and induces metaplasia-associated prostatic intraepithelial neoplasia (PIN) in aged mice. A: Periodic acidSchiff (PAS) staining showing areas of normal epithelium (left panel) and goblet cell metaplasia (right panel) in an miR-32 TG (miR-32) mouse prostate. The metaplastic area shows heightened epithelium with PAS-stained, mucin-secreting goblet cells (arrowheads) and thickened stroma with increased cellularity (asterisk). B: Relative occurrence of goblet cell metaplasia between different prostatic lobes in 16- to 24-month-old wild-type (wt) and miR-32 TG (miR-32) mice. C: A metaplastic area in miR-32 TG mouse with $\mathrm{Ki}-67$ immunostaining (brown) showing increased replicative activity and replicative crypt formation (asterisk). Examples of mucin-containing goblet cells are marked with arrowheads. D: Representative images of hematoxylin and eosin (H\&E), PAS, and Ki-67 immunohistochemical staining in areas of goblet cell metaplasia and adjacent PIN in aged (24 months) miR-32 TG mouse prostate. Top insets: Metaplastic areas. Bottom insets: PIN areas. Examples of goblet cells in PAS staining (arrowheads) and positive Ki-67 cells (arrows) are shown. Asterisk in PAS-stained image denotes secreted mucin. $n=28$ (B, wt mice); $n=37$ (B, miR-32 mice). Scale bars: $25 \mu \mathrm{m}$ (A, C, and $\mathbf{D}$, top and bottom insets); $100 \mu \mathrm{m}$ (D, main images). DP, dorsal prostate; LP, lateral prostate; VP, ventral prostate. lateral prostate, whereas the increase due to TG miR-32 expression occurred mostly in the ventral prostate $(P<0.001)$ (Figure 3B). The metaplastic areas were often associated with patched Ki-67 staining in areas resembling replicative crypt formation (Figure 3C). Interestingly, the miR-32 TG mice also demonstrated PIN that associated with the metaplastic areas. Of the analyzed mice, 4 of 25 miR-32 TG mice had a metaplasia-associated PIN lesion, as determined by increased intra-acinar cellularity and elevated Ki-67 positivity (Figure 3D), whereas no PIN lesions were found associated with metaplasia in the wt mice.

\section{Effects of miR-32 Expression on Gene Expression in the Mouse Prostate}

To assess the effects of miR-32 expression at the level of gene expression in the prostate, we performed a microarray analysis using RNA from ventral and dorsolateral prostates from wt and miR-32 TG mice. To focus on the potential direct miR-32 targets, we concentrated on genes with down-regulated expression. Up to 119 genes were found to be downregulated by at least twofold (Figure 4A and Supplemental
Table S1). Five of the down-regulated genes were predicted to be miR-32 targets by the Targetscan prediction program, with none in miRDB or microRNA.org. Of these predicted targets, Rac 2 represented a gene expressed in the epithelium, down-regulation of which in the ventral prostate was verified by RT-qPCR in two lines of miR-32 TG mice (Figure 4B). Next, we wanted to assess if human $R A C 2$ is regulated by miR-32. We transfected PC-3 prostate cancer cells with nontarget pre-miR-control or pre-miR-32, and performed RTqPCR. Figure 4C shows that miR-32 down-regulates endogenous RAC2 expression in human cells. As miR-32 expression is known to increase along with the PC progression in humans, being higher in primary $\mathrm{PC}$ and castration-resistant $\mathrm{PC}$ compared with benign prostatic hyperplasia, ${ }^{20}$ we next interrogated the expression levels of RAC2 in human PC samples using our previously generated RNA sequencing data. ${ }^{33}$ The analysis revealed that $R A C 2$ expression is significantly lower in PC $(P<0.05)$ and castration-resistant PC $(P<0.001)$ compared with benign prostatic hyperplasia (Figure 4D). An independent data set of clinical prostate cancer samples by Taylor et $\mathrm{al}^{37}$ shows that the samples with high miR-32 expression are likely to have low RAC2 levels (Figure 4E). 
A

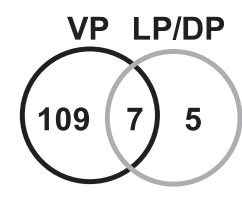

D

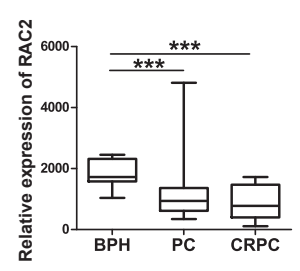

B

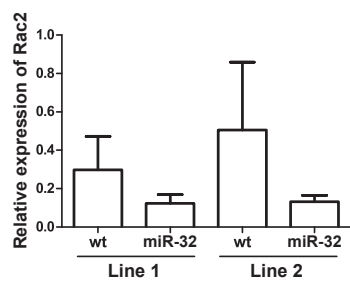

E

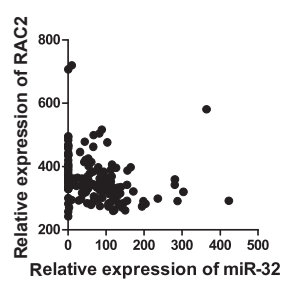

C

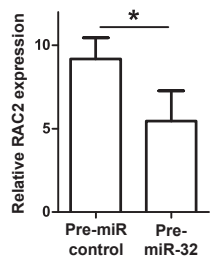

F

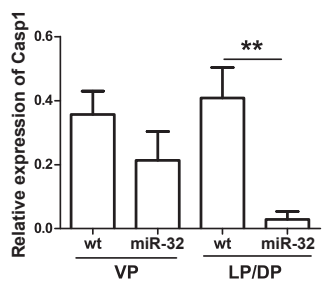

G

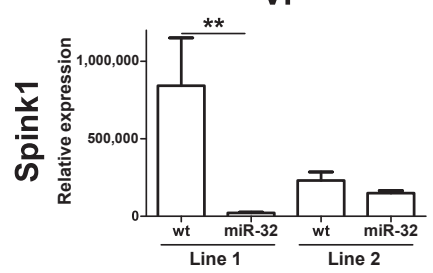

LP/DP

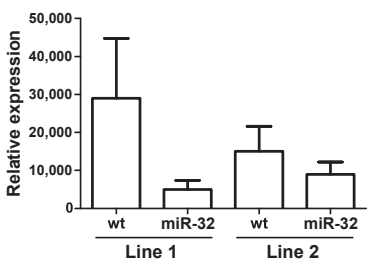

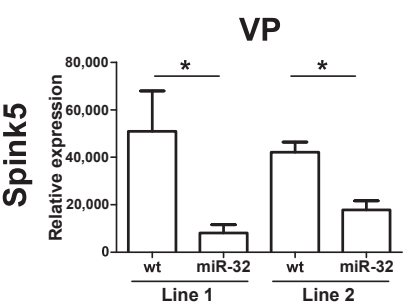

LP/DP

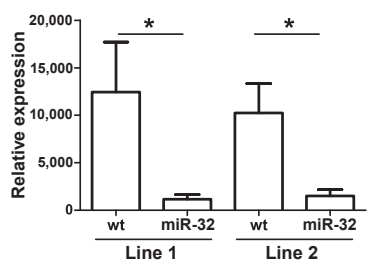

Figure 4 Effect of transgenic (TG) miR-32 on gene expression in the mouse prostate. A: Microarray analysis of gene expression in ventral (VP) and dorsolateral (LP/DP) prostates of 6-month-old mice. Venn diagram represents genes down-regulated by at least twofold in miR-32 TG mice compared with wild-type (wt) mice. Seven down-regulated genes common between VP and LP/DP samples were identified. B: Expression of Rac2 in ventral prostates in two miR-32 TG lines (lines 1 and 2) and wt mice assessed by quantitative RT-PCR (RT-qPCR). C: Expression of RAC2 in PC-3 cells transfected with either nontargeting control (pre-miR-control) or miR-32 (pre-miR-32) pre-miRNA constructs. D: Expression of RAC2 in a set of clinical prostate cancer samples (Ylipää et al ${ }^{33}$ ) of benign prostatic hyperplasia (BPH), primary prostate cancer (PC), and castration-resistant prostate cancer (CRPC). E: Expression of RAC2 relative to expression of miR-32 in a data set of clinical prostate cancer samples by Taylor et al. ${ }^{35} \mathrm{~F}$ : Expression of caspase (Casp) 1 in VP and LP/DP of wt and miR-32 TG (miR-32) mice, as assessed by RT-qPCR. G: Expression of Spink1 and Spink5 in VP and LP/DP representing two separate miR-32 TG lines (lines 1 and 2 ) and wt mice, assessed by RT-qPCR. $n=6$ (A and F, miR-32 TG and wt mice); $n=6$ to 7 in each group (B and G); $n=12$ (D, BPH group); $n=30$ (D, PC group); $n=13$ (D, (RPC group). ${ }^{*} P<0.05,{ }^{* *} P<0.01$, and ${ }^{* * * P}<0.001$.

Collectively, these results suggest that $R A C 2$ may represent a clinically relevant miR-32 target in human PC.

As we have previously shown miR-32 to affect apoptosis of PC cells in vitro, ${ }^{20}$ we searched for apoptotic effectors among the genes suggested to be down-regulated based on the microarray results. We found two caspases (Casp1 and Casp4) with lower expression in the TG prostate compared with the wt prostate, and performed RT-qPCR analysis for these genes. Although we could not confirm statistically significant downregulation of Casp4 (data not shown), Casp1 was downregulated specifically in the dorsolateral prostate $(P=0.008)$ (Figure $4 \mathrm{~F})$. The microarray results further indicated that seven genes were down-regulated by miR-32 throughout the prostate (namely, H2-Aa, H2-Ab1, Igh-VJ558, Saal, Saa3, Spink1, and Spink5). Of these genes, four (Saal, Saa3, Spink1, and Spink5) likely represented epithelial transcripts, and we, thus, performed RT-qPCR on them. Spink1 and Spink5 were confirmed to be down-regulated (Figure 4G). The expression of Spink1 exhibited a statistically significant decrease only in the ventral prostate of one of the two miR-32
TG mouse lines analyzed, although a similar trend was visible in the other mouse line as well. The expression of Spink5 was markedly decreased by the TG miR-32 overexpression in both ventral and dorsolateral prostates in both miR-32 TG mouse lines studied (Figure 4G).

\section{Effects of miR-32 Expression in Mouse Prostate in Heterozygous Pten Background}

To test whether miR-32 exerts an effect in neoplastic lesions formed in prostate tissue, we crossbred the miR-32 TG mice with mice heterozygous for the tumor suppressor Pten, and assessed prostate histology of $\mathrm{Pten}^{+/-}$and $\mathrm{miR}$-32xPten ${ }^{+/-}$ mice at 10 to 11 months of age. First, we analyzed whether miR-32 increases the replication potential of the histologically normal epithelium in the Pten $^{+/-}$background as well (Supplemental Figure S2A). The percentage of nuclei positive for $\mathrm{Ki}-67$ is increased in the normal-appearing epithelium of miR-32xPten ${ }^{+-}$mice compared with the Pten $^{+/-}$mice (Figure 5A). Second, we examined signs of 
A

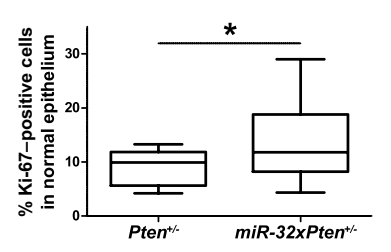

E

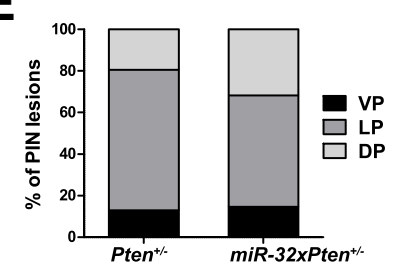

B

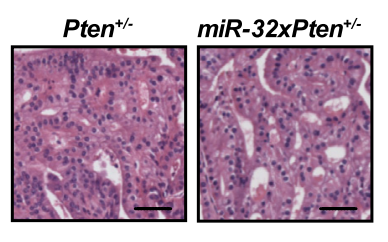

F

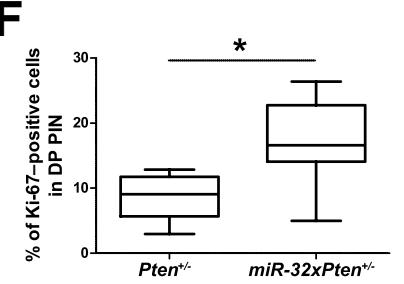

C

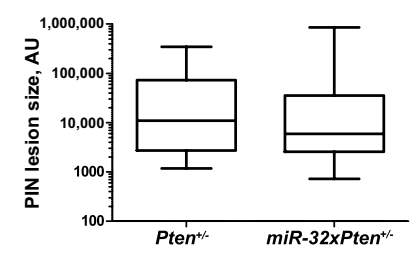

G

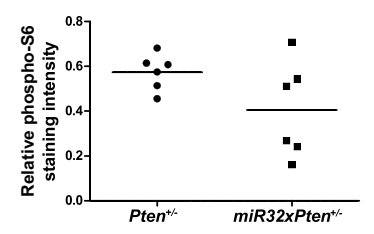

D

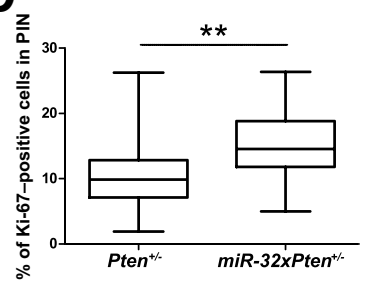

H

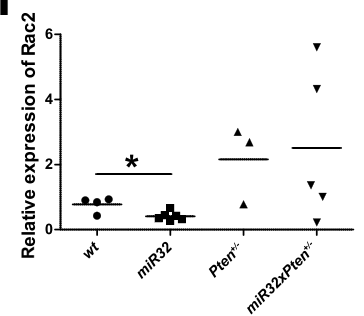

Figure 5 Transgenic (TG) expression of miR-32 promotes proliferation in histologically normal epithelium and prostatic intraepithelial neoplasia (PIN) lesions in the dorsal prostate of mice heterozygous for tumor-suppressor Pten. A-G: Histological assessment was performed using 10- to 11-month-old mice. A: Effect of TG miR-32 expression on replication activity of epithelium in Pten ${ }^{+/-}$mice with normal appearance, as assessed by immunohistochemistry for Ki67. B: Typical histology of PIN lesions in Pten ${ }^{+-}$and $m i R-32 x$ Pten $^{+/-}$mice with hematoxylin and eosin staining. C: Effect of TG miR-32 expression on size of PIN lesions in Pten ${ }^{+/-}$mice. D: Effect of TG miR-32 expression on replication activity of PIN lesions in Pten ${ }^{+/-}$mice, as measured by immunohistochemistry of Ki-67. E: Effect of TG miR-32 expression on distribution of PIN lesions between prostatic lobes in Pten ${ }^{+/-}$mice. F: Effect of TG miR-32 expression on replication activity of PIN lesions in the dorsal prostate (DP) in Pten ${ }^{+/-}$mice, as measured by immunohistochemistry of Ki-67. G: Effect of miR-32 expression on Akt/mammalian target of rapamycin pathway activity, as measured by immunohistochemistry of phosphorylated S6 on the PIN lesions of Pten ${ }^{+/-}$and miR32xPten ${ }^{+/-}$mice. H: Effect of TG miR-32 on expression of Rac2 in the prostates of 4-month-old Pten ${ }^{+/-}$model mice, as assessed by quantitative RT-PCR. $n=6$ in each group $(\mathbf{A}-\mathbf{G}) ; n=3$ to 6 in each group $(\mathbf{H}) ; n=31$ Pten $^{+/-}$mice $(\mathbf{C}$ and $\mathbf{E}) ; n=41$ miR-32xPten $^{+/-}$mice $(\mathbf{C}$ and $\mathbf{E}) .{ }^{*} P<0.05, * * P<0.01$. Scale bar $=50 \mu \mathrm{m}(\mathbf{B})$. AU, arbitrary unit; $L P$, lateral prostate; VP, ventral prostate.

increased metaplasia in the miR-32xPten ${ }^{+/-}$mice. The analysis revealed that only two of the six $\mathrm{Pten}^{+/-}$control mice had goblet cell metaplasia at one site, a rate similar to that found in wt mice. In contrast, five of six of the miR$32 \mathrm{Pten}^{+/-}$mice had metaplasia, and most of them at several locations $(P<0.012)$. Furthermore, the mean number of lesions per affected mouse was increased from one in $\mathrm{Pten}^{+/-}$mice to three in $\mathrm{miR}-32 \mathrm{xPten}^{+/-}$mice.

$\mathrm{Pten}^{+/-}$mice typically develop PIN lesions within 10 months, ${ }^{29,38}$ providing a further possibility to analyze the effect of miR-32 expression on PIN lesion formation. We found a slightly increased incidence of high-grade PIN in the miR-32xPten ${ }^{+-}$mice compared with the Pten ${ }^{+/-}$controls (6.8 versus 5.2 lesions, on average, per mice). However, the difference was not statistically significant. The average size, size distribution, and histological appearance of the lesions were similar in these genetic backgrounds (Figure 5, B and C), and no differences were found in the percentages of cells positive for PCNA, phosphorylated histone 3, or cleaved caspase-3 (data not shown). However, the presence of $\mathrm{Ki}-67-$ positive nuclei was significantly $(P<0.05)$ higher in the PIN lesions of miR-32xPten ${ }^{+/-}$ mice compared with those present in the $\mathrm{Pten}^{+/-}$mice (Figure 5D and Supplemental Figure S2B). A statistically significant difference was observed in PIN lesions located specifically in the dorsal prostate (Figure 5E), where incidence of the lesions was increased twofold by the expression of $m i R$-32 TG (from 1 to 2.16 lesions per mouse, on average). Furthermore, the percentage of Ki-67-positive cells in PIN lesions in dorsal prostate was prominently increased in a statistically significant manner $\left(\right.$ Pten $^{+/-}$ versus miR-32xPten ${ }^{+/-}$mice, $8.8 \%$ versus $17.7 \%$; $P=0.011$ ) (Figure 5F). In contrast, no difference in the percentage of Ki-67-positive nuclei due to TG miR-32 expression was observed in PIN lesions in the ventral prostate, and only a mild trend was present in the percentage of Ki-67-positive nuclei in PIN lesions in the lateral prostate (data not shown). Thus, TG miR-32 expression has the strongest effect in PIN lesion incidence and Ki-67 positivity in the dorsal prostate of the $\mathrm{Pten}^{+/-}$mice.

Because miR-32 has been shown to down-regulate PTEN in colorectal and hepatocellular cancers, ${ }^{25,26}$ and as PTENregulated pathways are central to prostate cancer formation, ${ }^{39}$ we addressed whether expression of miR-32 TG affects well-known signaling pathways in $\mathrm{Pten}^{+/-}$mice. We performed immunohistochemistry on the PIN lesions for phosphorylated S6, a protein phosphorylated by the S6-kinase regulated by the Akt/mammalian target of rapamycin pathways, ${ }^{39}$ as a measure of pathway activity. Phosphorylated S6 levels were somewhat decreased by miR-32 TG expression in the PIN lesions of Pten ${ }^{+-}$mice; however, the difference was not statistically significant (Figure $5 \mathrm{G}$ and Supplemental Figure S2C). To further assess miR-32 downstream effects, we asked whether the down-regulation of Rac2 by miR-32 is 
evident also in the ten $^{+/-}$mice, and performed RT-qPCR in samples from 4-month-old wt and miR-32xPten ${ }^{+/-}$mice. Similar to the results shown in Effects of miR-32 Expression on Gene Expression in the Mouse Prostate, Rac2 expression was lower in miR-32-expressing than wt tissues (Figure $5 \mathrm{H}$ ). However, in $\mathrm{Pten}^{+/-}$mouse prostate, expression of Rac2 was elevated in a manner not decreased by miR-32 (Figure $5 \mathrm{H}$ ).

\section{Discussion}

miRNAs regulate several cancer-related cellular functions and can operate as oncogenes or tumor-suppressor genes. In this work, we assessed the functions of miR-32 in vivo, an miRNA we previously identified as deregulated in PC. ${ }^{20}$ By overexpressing miR-32 tissue specifically in the prostate of TG mice, we found that miR-32 induces proliferative and metaplastic alterations in the prostate epithelium. Although the increased proliferation, accelerated by miR-32 overexpression, is visible already in young mice in both wt and Pten $^{+-}$genetic backgrounds, the metaplastic transformation and the associated PIN have a longer latency, appearing in aged mice. Furthermore, there are spatial differences in the strength of the effects induced by the TG miR-32 expression in the prostate. The incidence of metaplasia is increased predominantly in the ventral prostate, at the site of most prominent miR-32 expression. In contrast, the increased incidence of PIN and the most prominent increase in cell proliferation in the $\mathrm{Pten}^{+/-}$background occur in the dorsal prostate, at the site where miR-32 overexpression is lower compared with ventral and lateral prostates. This indicates differences in the outcome of miR32 actions in the different lobes of the prostate, and reflects the biological differences between mouse prostatic lobes, including differential tendency to neoplastic development. ${ }^{40}$

With immunohistochemical Ki-67 and PCNA staining, we observed an increase in replication potential in the prostate epithelium of miR-32 TG mice. Measuring the percentage of Ki-67-positive nuclei has long been used to reflect the replication activity of cancer cells. Although Ki-67 immunohistochemical staining is binary in the wt prostate epithelium, with either no staining or intense staining spanning the whole nucleus, in the miR-32 TG epithelium, a proportion of the Ki-67-positive nuclei contain a less intense staining. This may indicate that the levels of Ki-67 induced by miR-32 overexpression are not high per nucleus, on average. Whether this has functional relevance remains to be studied. The replication activity, as measured by percentage of PCNApositive cells, was prominent in the ventral prostate, suggesting that there may be lobe-specific differences in the miR-32 effect on proliferation. Despite the increase in proliferation marker positivity in the normal prostate epithelium in young adult mice, the effect of miR-32 overexpression on cellularity or tumor formation remained modest; the miR-32 TG epithelium does not present hyperplastic features, and only a minor increase in the incidence of PIN was noticed in aged animals. This is partly explained by lack of increased number of mitoses in the tissue, as demonstrated by phosphorylated histone 3 immunostaining. These results indicate that miR-32 may potentiate replication in the prostate epithelium, but a tumor-promoting effect likely requires further promotion of other steps in the cell cycle. Mouse prostate is known to be relatively resistant to tumor formation. ${ }^{40}$ Thus, several genetic alterations are likely needed to break the tumor-forming barrier of mouse prostate epithelium. To promote tumor progression in miR-32 TG mice, we introduced an additional genetic alteration in the prostate epithelium by crossing the miR-32 TG mice to Pten heterozygous mice, known to be susceptible to hyperplasia and high-grade PIN. ${ }^{29}$ Also in this genetic background, an increase in the incidence of PIN formation associated with miR-32 expression was noted, whereas no cancer formation was initiated.

The PIN lesions in miR-32-overexpressing mouse prostates were associated with goblet cell metaplasia. Spontaneous mucinous metaplasia is rarely detected in mouse prostate epithelium, and the incidence may depend on the mouse strain used. ${ }^{41}$ TG expression of miR-32 increased the incidence of this phenotypic alteration of prostate epithelium, the significance of which in relation to PC is currently unknown. It has been reported that the stimulus by transgenic oncogenic Ras induced intestinal metaplasia, with the appearance of goblet cells in addition to PIN formation. ${ }^{42}$ Mice null for Pten and overexpressing human $M Y C$ showed adenocarcinoma of the prostate, with focal intestinal metaplasia and high-grade PIN, ${ }^{43}$ despite the fact that metaplasia is not reported for either of the parental genetically modified mouse lines. A similar phenotype of prostate adenocarcinoma with focal intestinal metaplasia in a background of high-grade mouse PIN was reported in mice with conditional Pten loss, lacking one allele on $N k x 3.1$ and expressing an activated K-ras mutant. ${ }^{44}$ Deletion of $A R$ in prostate epithelial cells of Pten-null mice, reported to develop adenocarcinoma in dorsolateral lobes, ${ }^{45}$ was found also to induce focal goblet cell metaplasia. ${ }^{46}$ Thus, goblet cell metaplasia has been shown to be associated with neoplastic transformation of mouse prostate epithelium in several genetically modified mouse models, including the miR-32 TG mice reported in the present study, whereas its potential role in PIN formation is not known. Our finding clearly indicated that the replicative activity of the epithelium in the metaplastic areas is increased by miR-32 expression, and the increase in goblet cell metaplasia and the accompanying increase in replicative activity may be signs of a potential oncogenic role of miR-32.

As miRNAs are parts of complex regulatory networks, and their pool of targets can vary cell type and context dependently, confirming the specific miRNA targets in particular situations is important, but challenging. ${ }^{5,7}$ miR-32 has been previously shown to post-transcriptionally downregulate the tumor-suppressor gene Pten in colorectal and hepatocellular cancers. ${ }^{25,26}$ However, in the present study, 
we found no evidence of down-regulation of Pten expression in miR-32 TG mouse prostate compared with the wt controls (data not shown). There was also not a statistically significant effect on Akt/mammalian target of rapamycin pathway activity, as measured via phosphorylation of a downstream target, S6. We did not find evidence for downregulation of the previously identified, prostate cancer-related miR-32 targets $\mathrm{Bim}^{21}$ or Btg $2^{20}$ in our miR-32 TG mouse material (data not shown). These results indicate differences in the miR-32 targets between mouse and human prostate, between tissues and cell lines, and/or between normal and cancerous tissues.

In this study, we used three databases for collecting the predicted targets for miR-32. However, a surprisingly low number of the predicted miR-32 targets was found to be down-regulated in the microarray-based gene expression analysis of miR-32 TG mouse prostate. Rac2, a small GTPbinding protein of the Rho family, was among those whose decreased expression was verified by both microarray and RT-qPCR. Interestingly, the ability of miR-32 to downregulate expression of Rac2 was overridden by decreased expression of Pten in our mouse model. We further confirmed decreased expression of RAC2 in cultured human prostate cancer cells transfected with pre-miR-32. Furthermore, we found that RAC2 expression is significantly lower in clinical PC samples compared with benign prostatic hyperplasia samples, thus showing opposite behavior compared with miR-32 expression. ${ }^{20}$ In fact, from the data set published by Taylor et al, ${ }^{37}$ it can be clearly seen that the samples with high miR-32 expression are likely to have low RAC2 levels and vice versa, supporting the idea that miR32 may contribute to keeping low levels of RAC2. These results suggest that RAC2 is a clinically relevant miR-32 target in PC. RAC2 has previously been considered hematopoiesis specific ${ }^{47}$; hence, the few data available of its functions in epithelial cells and solid tumors should be complemented in future studies. Interestingly, RAC2 has recently been identified as one of the best proteomic peptide predictors of relapse after adjuvant chemotherapy in patients with triple-negative breast cancer. ${ }^{48}$

A large fraction of mRNAs down-regulated by twofold or more in both ventral and dorsolateral prostates were likely originated from cell types of the immune system. These unlikely represent direct miR-32 targets as the promoter governing miR-32 expression is highly specific to the prostate epithelium, ${ }^{36}$ and we see no evidence of transgene expression in lymphatic tissue. However, these may represent secondary, but important, effects worth studying in the future. The remaining pool of down-regulated genes is likely to include both secondary effectors and direct miR-32 targets not predicted by the current database algorithms. The down-regulation of two protease inhibitors, Spink 1 and Spink5, was interesting because of the previously identified role of SPINK1 in human PC, ${ }^{49}$ and the increased SPINK1 expression in high-grade PCs. ${ }^{50}$ The protein has been suggested to be a therapeutic target in a subset of patients with
SPINK $1^{+} /$ETS $^{-}$PC,${ }^{51}$ and, accordingly, SPINK1 has been shown to affect invasion capabilities of PC cells. ${ }^{51,52}$ However, the Spinks are not predicted miR-32 targets, and their down-regulation mechanism by miR-32 needs further assessment.

As we have previously shown miR-32 to lower the rate of apoptosis in LNCaP PC cells in vitro, ${ }^{20}$ we searched for apoptotic effectors among the mRNAs down-regulated by miR-32 expression in the prostate in vivo. As a result, we observed that the expression of Caspl, a gene coding for an apoptotic effector cysteine protease caspase 1, was downregulated in the dorsolateral prostate. However, in assessing the rate of apoptosis in the prostate tissue, we found no evidence of decreased apoptosis by TG miR-32 expression in either normal epithelium or PIN lesions in the Pten $^{+-}$ background. Because the rate of apoptosis is extremely low under both of these circumstances (mean rates of cells positive for cleaved caspase- 3 are $0.5 \%$ and $1 \%$, respectively), the effect of miR-32 TG expression on apoptosis should be addressed also in an induced apoptotic model.

The relevance of our results for human cancer remains to be assessed further. As miRNAs are recognized regulators of gene expression and cancer, ${ }^{9}$ their potential as cancer markers and/or drug targets is under active investigation in PC. ${ }^{8}$ Because miR-32 is one of the miRNAs whose expression is most consistently increased in $\mathrm{PC},{ }^{20-23}$ it may be a potential inhibitory target for PC treatment, if the tumors depend on its functions. New drug targets are required, especially against the castration-resistant, lethal form of the disease, for which there currently exists no curative treatments, and in which miR-32 levels are most elevated. In the in vivo model presented herein, we found that elevated expression of miR-32 is able to transform mouse prostate epithelium, and it seems able to potentiate the proliferation capacity of the tissue. However, as the effect of miR-32 in promotion of prostate cancer may be dependent on the genetic context, more studies are required to dissect the genetic and gene expression makeup of the tumors of patients who may benefit from miR-32 down-regulation.

In conclusion, we have shown that overexpression of miR-32 in the mouse prostate increases proliferation, goblet cell metaplasia, and metaplasia-associated PIN in the prostate epithelium. Although miR-32 expression clearly has profound effects on the replication potential of prostate epithelial cells, the effect on PIN lesion size and number in the Pten heterozygous model remained modest. It is possible that the overexpression of miR-32 has a context-dependent effect not fully revealed by heterozygous deletion of a tumor-suppressor gene in a model that develops preneoplastic lesions, but not cancer. The potential tumorpromoting role of miR-32 should be further tested in a genetic model with a stronger oncogenic stimulus. Thus, transgenic expression of miR-32 in a mouse model developing prostate adenocarcinoma (eg, Hi-Myc model overexpressing the $M y c$ oncogene) is an essential task for the future. 


\section{Acknowledgments}

We thank Osku Alanen, Melissa Bothe, M.Sc., Alvaro Haroun Izquierdo, M.Sc., Jenni Jouppila, M.Sc., AnnaMaija Kakkonen, M.Sc., Sonja Koivukoski, Konsta Kukkonen, M.Sc., Katja Liljeström, Päivi Martikainen, Carol McMenemy, M.Sc., Theano Panagopoulou, M.Sc., Marika Vähä-Jaakkola, and the staff of Turku Center for Disease Modelling for skillful technical assistance.

\section{Supplemental Data}

Supplemental material for this article can be found at http://dx.doi.org/10.1016/j.ajpath.2017.07.012.

\section{References}

1. Jemal A, Bray F, Center MM, Ferlay J, Ward E, Forman D: Global cancer statistics. CA Cancer J Clin 2011, 61:69-90

2. Knudsen KE, Kelly WK: Outsmarting androgen receptor: creative approaches for targeting aberrant androgen signaling in advanced prostate cancer. Expert Rev Endocrinol Metab 2011, 6:483-493

3. Schröder FH, Hugosson J, Roobol MJ, Tammela TL, Ciatto S, Nelen V, Kwiatkowski M, Lujan M, Lilja H, Zappa M, Denis LJ, Recker F, Berenguer A, Määttänen L, Bangma CH, Aus G, Villers A, Rebillard X, van der Kwast T, Blijenberg BG, Moss SM, de Koning HJ, Auvinen A; ERSPC Investigators: Screening and prostate-cancer mortality in a randomized European study. N Engl J Med 2009, 360:1320-1328

4. Lagos-Quintana M, Rauhut R, Lendeckel W, Tuschl T: Identification of novel genes coding for small expressed RNAs. Science 2001, 294: 853-858

5. He L, Hannon GJ: MicroRNAs: small RNAs with a big role in gene regulation. Nat Rev Genet 2004, 5:522-531

6. Olena AF, Patton JG: Genomic organization of microRNAs. J Cell Physiol 2010, 222:540-545

7. Thomas M, Lieberman J, Lal A: Desperately seeking microRNA targets. Nat Struct Mol Biol 2010, 17:1169-1174

8. Catto JW, Alcaraz A, Bjartell AS, De Vere White R, Evans CP, Fussel S, Hamdy FC, Kallioniemi O, Mengual L, Schlomm T, Visakorpi T: MicroRNA in prostate, bladder, and kidney cancer: a systematic review. Eur Urol 2011, 59:671-681

9. Di Leva G, Croce CM: Roles of small RNAs in tumor formation. Trends Mol Med 2010, 16:257-267

10. Porkka KP, Pfeiffer MJ, Waltering KK, Vessella RL, Tammela TL, Visakorpi T: MicroRNA expression profiling in prostate cancer. Cancer Res 2007, 67:6130-6135

11. Tong AW, Fulgham P, Jay C, Chen P, Khalil I, Liu S, Senzer N, Eklund AC, Han J, Nemunaitis J: MicroRNA profile analysis of human prostate cancers. Cancer Gene Ther 2009, 16:206-216

12. Schaefer A, Jung M, Mollenkopf HJ, Wagner I, Stephan C, Jentzmik F, Miller K, Lein M, Kristiansen G, Jung K: Diagnostic and prognostic implications of microRNA profiling in prostate carcinoma. Int J Cancer 2010, 126:1166-1176

13. Szczyrba J, Löprich E, Wach S, Jung V, Unteregger G, Barth S, Grobholz R, Wieland W, Stöhr R, Hartmann A, Wullich B, Grässer F: The microRNA profile of prostate carcinoma obtained by deep sequencing. Mol Cancer Res 2010, 8:529-538

14. Martens-Uzunova ES, Jalava SE, Dits NF, van Leenders GJ, Møller S, Trapman J, Bangma CH, Litman T, Visakorpi T, Jenster G: Diagnostic and prognostic signatures from the small non-coding RNA transcriptome in prostate cancer. Oncogene 2012, 31:978-991
15. Walter BA, Valera VA, Pinto PA, Merino MJ: Comprehensive microRNA profiling of prostate cancer. J Cancer 2013, 4: 350-357

16. Hart M, Nolte E, Wach S, Szczyrba J, Taubert H, Rau TT, Hartmann A, Grässer FA, Wullich B: Comparative microRNA profiling of prostate carcinomas with increasing tumor stage by deep sequencing. Mol Cancer Res 2014, 12:250-263

17. Song C, Chen H, Wang T, Zhang W, Ru G, Lang J: Expression profile analysis of microRNAs in prostate cancer by next-generation sequencing. Prostate 2015, 75:500-516

18. Fabris L, Ceder Y, Chinnaiyan AM, Jenster GW, Sorensen KD, Tomlins S, Visakorpi T, Calin GA: The potential of microRNAs as prostate cancer biomarkers. Eur Urol 2016, 70:312-322

19. Wang YL, Wu S, Jiang B, Yin FF, Zheng SS, Hou SC: Role of microRNAs in prostate cancer pathogenesis. Clin Genitourin Cancer 2015, 13:261-270

20. Jalava SE, Urbanucci A, Latonen L, Waltering KK, Sahu B, Jänne OA, Seppälä J, Lähdesmäki $H$, Tammela TL, Visakorpi T: Androgen-regulated miR-32 targets BTG2 and is overexpressed in castration-resistant prostate cancer. Oncogene 2012, 31:4460-4471

21. Ambs S, Prueitt RL, Yi M, Hudson RS, Howe TM, Petrocca F, Wallace TA, Liu CG, Volinia S, Calin GA, Yfantis HG, Stephens RM, Croce CM: Genomic profiling of microRNA and messenger RNA reveals deregulated microRNA expression in prostate cancer. Cancer Res 2008, 68:6162-6170

22. Leite KR, Tomiyama A, Reis ST, Sousa-Canavez JM, Sañudo A, Camara-Lopes LH, Srougi M: MicroRNA expression profiles in the progression of prostate cancer: from high-grade prostate intraepithelial neoplasia to metastasis. Urol Oncol 2013, 31:796-801

23. Liao H, Xiao Y, Hu Y, Xiao Y, Yin Z, Liu L: microRNA-32 induces radioresistance by targeting DAB2IP and regulating autophagy in prostate cancer cells. Oncol Lett 2015, 10:2055-2062

24. Aakula A, Kohonen P, Leivonen SK, Mäkelä R, Hintsanen P, Mpindi JP, Martens-Uzunova E, Aittokallio T, Jenster G, Perälä M, Kallioniemi O, Östling P: Systematic identification of microRNAs that impact on proliferation of prostate cancer cells and display changed expression in tumor tissue. Eur Urol 2016, 69:1120-1128

25. Wu W, Yang J, Feng X, Wang H, Ye S, Yang P, Tan W, Weig G, Zhou Y: MicroRNA-32 (miR-32) regulates phosphatase and tensin homologue (Pten) ex-pression and promotes growth, migration, and invasion in colorectal carcinoma cells. Mol Cancer 2013, 12:30

26. Yan SY, Chen MM, Li GM, Wang YQ, Fan JG: MiR-32 induces cell proliferation, migration, and invasion in hepatocellular carcinoma by targeting PTEN. Tumour Biol 2015, 36:4747-4755

27. Waltering KK, Helenius MA, Sahu B, Manni V, Linja MJ, Jänne OA, Visakorpi $\mathrm{T}$ : Increased expression of androgen receptor sensitizes prostate cancer cells to low levels of androgens. Cancer Res 2009, 69: $8141-8149$

28. Latonen L, Leinonen KA, Grönlund T, Vessella RL, Tammela TL, Saramäki OR, Visakorpi T: Amplification of the 9p13.3 chromosomal region in prostate cancer. Genes Chromosomes Cancer 2016, 55: 617-625

29. Di Cristofano A, Pesce B, Cordon-Cardo C, Pandolfi PP: Pten is essential for embryonic development and tumour suppression. Nat Genet 1998, 19:348-355

30. Tuominen VJ, Isola J: Linking whole-slide microscope images with DICOM by using JPEG2000 interactive protocol. J Digit Imaging 2010, 23:454-462

31. Tuominen VJ, Isola J: The application of JPEG2000 in virtual microscopy. J Digit Imaging 2009, 22:250-258

32. Schneider CA, Rasband WS, Eliceiri KW: "NIH Image to ImageJ: 25 years of image analysis." Nat Methods 2012, 9:671-675

33. Park JH, Walls JE, Galvez JJ, Kim M, Abate-Shen C, Shen MM, Cardiff RD: Prostatic intraepithelial neoplasia in genetically engineered mice. Am J Pathol 2002, 161:727-735

34. Mi H, Muruganujan A, Thomas PD: PANTHER in 2013: modeling the evolution of gene function, and other gene attributes, in the 
context of phylogenetic trees. Nucleic Acids Res 2013, 41(database issue):D377-D386

35. Ylipää A, Kivinummi K, Kohvakka A, Annala M, Latonen L, Scaravilli M, Kartasalo K, Leppänen SP, Karakurt S, Seppälä J, YliHarja O, Tammela TL, Zhang W, Visakorpi T, Nykter M: Transcriptome sequencing reveals PCAT5 as a novel ERG-regulated long noncoding RNA in prostate cancer. Cancer Res 2015, 75:4026-4031

36. Zhang J, Thomas TZ, Kasper S, Matusik RJ: A small composite probasin promoter confers high levels of prostate-specific gene expression through regulation by androgens and glucocorticoids in vitro and in vivo. Endocrinology 2000, 141:4698-4710

37. Taylor BS, Schultz N, Hieronymus H, Gopalan A, Xiao Y, Carver BS, Arora VK, Kaushik P, Cerami E, Reva B, Antipin Y, Mitsiades N, Landers T, Dolgalev I, Major JE, Wilson M, Socci ND, Lash AE, Heguy A, Eastham JA, Scher HI, Reuter VE, Scardino PT, Sander C, Sawyers CL, Gerald WL: Integrative genomic profiling of human prostate cancer. Cancer Cell 2010, 18:11-22

38. Chen ML, Xu PZ, Peng XD, Chen WS, Guzman G, Yang X, Di Cristofano A, Pandolfi PP, Hay N: The deficiency of Akt1 is sufficient to suppress tumor development in Pten $+/-$ mice. Genes Dev 2006, 20:1569-1574

39. Sarker D, Reid AH, Yap TA, de Bono JS: Targeting the PI3K/AKT pathway for the treatment of prostate cancer. Clin Cancer Res 2009, 15:4799-4805

40. Shappell SB, Thomas GV, Roberts RL, Herbert R, Ittmann MM, Rubin MA, Humphrey PA, Sundberg JP, Rozengurt N, Barrios R, Ward JM, Cardiff RD: Prostate pathology of genetically engineered mice: definitions and classification: the consensus report from the Bar Harbor meeting of the Mouse Models of Human Cancer Consortium Prostate Pathology Committee. Cancer Res 2004, 64:2270-2305

41. Latonen L, Kujala P, Visakorpi T: Incidence of mucinous metaplasia in the prostate of FVB/N mice (Mus musculus). Comp Med 2016, 66: 286-289

42. Scherl A, Li JF, Cardiff RD, Schreiber-Agus N: Prostatic intraepithelial neoplasia and intestinal metaplasia in prostates of probasinRAS transgenic mice. Prostate 2004, 59:448-459

43. Clegg NJ, Couto SS, Wongvipat J, Hieronymus H, Carver BS, Taylor BS, Ellwood-Yen K, Gerald WL, Sander C, Sawyers CL: MYC cooperates with AKT in prostate tumorigenesis and alters sensitivity to mTOR inhibitors. PLoS One 2011, 6:e17449
44. Ittmann M, Huang J, Radaelli E, Martin P, Signoretti S, Sullivan R, Simons BW, Ward JM, Robinson BD, Chu GC, Loda M, Thomas G, Borowsky A, Cardiff RD: Animal models of human prostate cancer: the consensus report of the New York meeting of the Mouse Models of Human Cancers Consortium Prostate Pathology Committee. Cancer Res 2013, 73:2718-2736

45. Mulholland DJ, Tran LM, Li Y, Cai H, Morim A, Wang S, Plaisier S, Garraway IP, Huang J, Graeber TG, Wu H: Cell autonomous role of PTEN in regulating castration-resistant prostate cancer growth. Cancer Cell 2011, 19:792-804

46. Mak P, Li J, Samanta S, Chang C, Jerry DJ, Davis RJ, Leav I, Mercurio AM: Prostate tumorigenesis induced by PTEN deletion involves estrogen receptor $\beta$ repression. Cell Rep 2015, 10:1982-1991

47. Pai SY, Kim C, Williams DA: Rac GTPases in human diseases. Dis Markers 2010, 29:177-187

48. Gámez-Pozo A, Trilla-Fuertes L, Prado-Vázquez G, Chiva C, LópezVacas R, Nanni P, Berges-Soria J, Grossmann J, Díaz-Almirón M, Ciruelos E, Sabidó E, Espinosa E, Fresno Vara JÁ: Prediction of adjuvant chemotherapy response in triple negative breast cancer with discovery and targeted proteomics. PLoS One 2017, 12:e0178296

49. Tomlins SA, Rhodes DR, Yu J, Varambally S, Mehra R, Perner S, Demichelis F, Helgeson BE, Laxman B, Morris DS, Cao Q, Cao X, Andrén O, Fall K, Johnson L, Wei JT, Shah RB, Al-Ahmadie H, Eastham JA, Eggener SE, Fine SW, Hotakainen K, Stenman UH, Tsodikov A, Gerald WL, Lilja H, Reuter VE, Kantoff PW, Scardino PT, Rubin MA, Bjartell AS, Chinnaiyan AM: The role of SPINK1 in ETS rearrangement-negative prostate cancers. Cancer Cell 2008, 13:519-528

50. Paju A, Hotakainen K, Cao Y, Laurila T, Gadaleanu V, Hemminki A, Stenman UH, Bjartell A: Increased expression of tumor-associated trypsin inhibitor, TATI, in prostate cancer and in androgenindependent 22Rv1 cells. Eur Urol 2007, 52:1670-1679

51. Ateeq B, Tomlins SA, Laxman B, Asangani IA, Cao Q, Cao X, Li Y, Wang X, Feng FY, Pienta KJ, Varambally S, Chinnaiyan AM: Therapeutic targeting of SPINK1-positive prostate cancer. Sci Trans1 Med 2011, 3:72ra17

52. Wang C, Wang L, Su B, Lu N, Song J, Yang X, Fu W, Tan W, Han B: Serine protease inhibitor Kazal type 1 promotes epithelialmesenchymal transition through EGFR signaling pathway in prostate cancer. Prostate 2014, 74:689-701 